\title{
A systematic review of patient-reported measures of burden of treatment in three chronic diseases
}

This article was published in the following Dove Press journal:

Patient Related Outcome Measures

4 June 2013

Number of times this article has been viewed

\author{
David T Eton' \\ Tarig A Elraiyah ${ }^{2}$ \\ Kathleen J Yost ${ }^{3}$ \\ Jennifer L Ridgeway' \\ Anna Johnson ${ }^{2}$ \\ Jason S Egginton' \\ Rebecca J Mullan ${ }^{4}$ \\ Mohammad Hassan Murad ${ }^{2}$ \\ Patricia J Erwin ${ }^{2}$ \\ Victor M Montori ${ }^{1,2}$ \\ 'Division of Heath Care Policy and \\ Research, Department of Health \\ Sciences Research, ${ }^{2}$ Knowledge and \\ Evaluation Research Unit, ${ }^{3}$ Division of \\ Epidemiology, Department of Health \\ Sciences Research, Mayo Clinic, \\ Rochester, MN, USA; ${ }^{4}$ University \\ of Minnesota Medical School, \\ Minneapolis, MN, USA
}

Correspondence: David T Eton Mayo Clinic, 200 First Street SW, Rochester, MN 55905, USA

Tel +I 5072931353

Fax + I 507284 I5I6

Email eton.david@mayo.edu
Background: Burden of treatment refers to the workload of health care and its impact on patient functioning and well-being. There are a number of patient-reported measures that assess burden of treatment in single diseases or in specific treatment contexts. A review of such measures could help identify content for a general measure of treatment burden that could be used with patients dealing with multiple chronic conditions. We reviewed the content and psychometric properties of patient-reported measures that assess aspects of treatment burden in three chronic diseases, ie, diabetes, chronic kidney disease, and heart failure.

Methods: We searched Ovid MEDLINE, Ovid EMBASE, Ovid PsycINFO, and EBSCO CINAHL through November 2011. Abstracts were independently reviewed by two people, with disagreements adjudicated by a third person. Retrieved articles were reviewed to confirm relevance, with patient-reported measures scrutinized to determine consistency with the definition of burden of treatment. Descriptive information and psychometric properties were extracted.

Results: A total of 5686 abstracts were identified from the database searches. After abstract review, 359 full-text articles were retrieved, of which 76 met our inclusion criteria. An additional 22 articles were identified from the references of included articles. From the 98 studies, 57 patient-reported measures of treatment burden (full measures or components within measures) were identified. Most were multi-item scales (89\%) and assessed treatment burden in diabetes (82\%). Only 15 measures were developed using direct patient input and had demonstrable evidence of reliability, scale structure, and multiple forms of validity; six of these demonstrated evidence of sensitivity to change. We identified 12 content domains common across measures and disease types.

Conclusion: Available measures of treatment burden in single diseases can inform derivation of a patient-centered measure of the construct in patients with multiple chronic conditions. Patients should take part in developing the measure to ensure salience and relevance.

Keywords: patient-reported outcomes, treatment burden, questionnaire, psychometric properties, self-management, patient-centered

\section{Introduction}

Burden of treatment is the workload of health care and its impact on patient functioning and well-being. "Workload" consists of the demands placed on a patient by treatment for condition(s) and any associated self-care (eg, health monitoring, diet, exercise). "Impact" refers to the effect of treatment and self-care on a patient's behavioral, cognitive, physical, and psychosocial well-being. Burden of treatment is an important clinical issue because it can lead to lower rates of adherence with prescribed treatments and self-care, ${ }^{2,3}$ and ultimately result in worse clinical outcomes, including more hospitalizations, ${ }^{4}$ higher mortality, ${ }^{4,5}$ and poorer health-related quality of life. ${ }^{6,7}$ In order 
to understand better how burden of treatment can influence critical patient outcomes, robust means of measuring it must be available. Like health-related quality of life, burden of treatment is best understood from the perspective of the individual patient. Hence, it is best assessed through direct patient query.

Patients coping with multiple chronic health conditions are especially vulnerable to a sense of burden with their treatment regimen because they are often required to engage in a complex array of self-care activities in order to maintain health. ${ }^{8}$ The number of US adults with multiple chronic health conditions is projected to rise from 57 million in 2000 to 81 million by $2020 .^{9}$ There is a paucity of available options for assessing burden of treatment in this growing patient population, ${ }^{10}$ including no comprehensive, multidomain patient-reported measure (PRM). However, there are a number of PRMs that assess burden of treatment in single diseases or specific treatments. A review of such measures, focused specifically on identifying similarities in content across diseases and treatment, could help to determine the content for a general comprehensive measure of treatment burden, that is amenable for use across chronic diseases or with patients coping with more than one health condition.

Building a new PRM relies on triangulation of multiple and diverse methods, often used in a stepwise fashion. ${ }^{1-14}$ The first steps usually involve direct patient query of the phenomena of interest and a literature review of existing instruments in related areas. ${ }^{11,14}$ We outlined a preliminary measurement framework of treatment burden in a recent study. ${ }^{1}$ The framework was derived from 32 semistructured interviews with patients, all with complex self-care regimens (including polypharmacy) and most coping with multiple chronic health conditions. The framework is currently undergoing further qualitative testing in a new sample of socioeconomically disadvantaged patients. Currently, there are no systematic reviews of PRMs of treatment burden. The review of PRMs described in this report is designed to augment and verify the developing measurement framework, while also informing item content for a new comprehensive measure of treatment burden.

We searched the available scientific literature for PRMs of treatment burden in three disease types, ie, diabetes, chronic kidney disease, and heart failure. These three chronic diseases were selected because they all can involve rather complicated long-term management plans requiring considerable time, effort, and financial investment from patients, ${ }^{6,15,16}$ and because of their interrelationship with one another, including the fact that diagnosis of one can raise the risk of diagnosis of the others. ${ }^{17}$ The PRMs identified contain components consistent with our above definition of treatment burden and could include full scales, scales within measures, or other scorable components, like single items. The systematic review has three objectives. First, to identify PRMs of treatment burden in diabetes, chronic kidney disease, and heart failure, including full measures, scales within measures, or other scorable components within measures; second, to identify common content domains of treatment burden, given that common domains that cut across measures and disease types can help inform the content of a general measure of treatment burden; and third, to summarize measure characteristics and psychometric properties, eg, reliability, scaling structure, validity, and sensitivity to change. While documentation of these performance characteristics could help investigators to select an appropriate measure of treatment burden for use in the diseases targeted, the primary aim of this summary is to identify psychometrically sound measures, scales, and items that can inform the content of a general (not disease-specific) measure of burden.

\section{Materials and methods Database search and abstract review}

We searched Ovid MEDLINE, Ovid EMBASE, Ovid PsycINFO, and EBSCO CINAHL (Cumulative Index to Nursing and Allied Health Literature) through November 2011. An information specialist (PJE) created and ran the search strategies. Sample terms used in the searches included "self-care", "workload", "burden", and "lifestyle" crossed with "questionnaire", "scale", "measure", and "survey" and the three targeted diseases, diabetes (types 1 and 2), chronic kidney disease, and heart failure. Full search strategies for each database are accessible at http://mayoresearch.mayo. edu/mayo/research/hsr/burden-of-treatment.cfm.

Abstracts were downloaded into a reference software library (Endnote $\mathrm{X} 4^{\circledR}$ ), then uploaded to a web-based systematic review software program (DistillerSR) where they were reviewed. All abstracts were double-reviewed for relevance and fit with the inclusion criterion of an article reflecting original research describing the development, validation, or use of a PRM of treatment burden in diabetes, chronic kidney disease, or heart failure. To assist reviewers in selecting appropriate measures, a working definition was provided on the abstraction form ("the burden of treatment is the negative impact of treatment and care on a patient's daily routine through the investment of time, money, and effort into health care"). Disagreements between abstract reviewers were adjudicated by either DTE or KJY, given 
their expertise with PRMs and familiarity with the burden of treatment construct that was discussed by these two authors prior to and during adjudication.

\section{Article retrieval, determination of inclusion, and data extraction}

Full-text articles of relevant abstracts were retrieved, uploaded to DistillerSR, and screened for relevance by DTE and KJY. Together, these authors carefully scrutinized each article, reviewing the items on each PRM (as included in the article or as identified through additional search for the actual measure), and determining which aspects of each measure were consistent with the working definition of treatment burden. This step was critical because in many instances an entire measure was not relevant, but portions of it were (eg, subscales). The components of each measure consistent with our definition of treatment burden were eligible for data extraction. A component (ie, full measure or subscale within a measure) was included for extraction if at least half of its items reflected treatment burden. Reference sections of the included articles were a secondary source of relevant articles missed by the database searches.

Any English language article describing the development or use of a PRM of treatment burden (as defined above) in one of the targeted diseases was included for data extraction. Articles were excluded if they: did not develop, validate, or use a PRM of treatment burden; did not provide any psychometric characteristics of the measure; described a product or device-specific patient preference or satisfaction measure; employed questionable methods (eg, very small sample sizes); or did not describe an original research study. For each article, data extractors were provided with the name of the measure as well as the component(s) of the measure that reflected treatment burden. They were instructed to extract descriptive information about the study (eg, sample size, age and gender of participants, disease focus) and psychometric data on the measure. When available, the following psychometric information were extracted for each measure: whether direct patient input was used during development; reliability, specifically internal consistency and test-retest; scale analysis, specifically factor analysis and item-total correlations; convergent and discriminant validity, ie, convergence with conceptually similar measures and divergence with conceptually dissimilar measures; known-groups validity or the ability of the PRM to differentiate known patient groups; concurrent validity or correlation of the PRM with meaningful clinical characteristics; and sensitivity to change or the ability of the PRM to reflect underlying change in patient status over time.
Data extractors (JLR, AJ, JSE) were trained by DTE. Prior to beginning the task, each extractor completed two sample extractions, with their results checked and didactic feedback provided by DTE, who also provided continued scientific support throughout the process. The extraction form was created by RJM, and TAE maintained the DistillerSR database, managed the extraction process including reviewer assignments, and provided technical support. All data extractions were checked for accuracy by one of the PRM experts (DTE or KJY).

\section{Results}

\section{Study screening and inclusion}

Figure 1 shows the process by which studies were screened and selected for inclusion. The database search yielded 5686 articles, of which 359 were retrieved for full-text review. After review of the full texts, 283 articles were excluded from further consideration, mostly because they did not develop, validate, or use a PRM of treatment burden. Several retained articles referenced other studies of possible relevance. Twenty-two of these were retrieved and deemed eligible for data extraction. Hence, a total of 98 articles were targeted for data extraction.

\section{Identified measures of treatment burden}

Fifty-seven PRMs of treatment burden were identified in the 98 articles selected for inclusion (see Table 1 for a list of the measures). Most (47, 82\%) assessed treatment burden in diabetes, but six (11\%) assessed treatment burden in kidney disease and four (7\%) in heart failure. Based on their focus and contents, we categorized the measures into one of the following eight types: treatment/regimen-related impact and burden, barriers to self-care, distress, insulin treatment, family conflict/strain, general diabetes quality of life, glucose monitoring, or treatment satisfaction. Most of the measures represented in Table $1(51,89 \%)$ are scored as multi-item scales (ie, multiple items are combined to form a single score). The rest $(6,11 \%)$ score responses to only single items. This includes measures made up of only a single, standalone item ${ }^{18-20}$ as well as measures made up of multiple items that report scores for only individual items (eg, Survey of Treatment Burdens in Diabetes, ${ }^{2,21}$ Perceived Difficulties in Diabetes Self-Care, ${ }^{22}$ and Perceptions of Insulin Shots and Fingersticks ${ }^{23}$ ). Finally, some measures $(12,21 \%$, all in diabetes) are suitable for administration in children or adolescents, including a few that are specifically tailored to this population (eg, the DISABKIDS Diabetes module $^{24}$ and the Pediatric Quality of Life Inventory 3.0 Diabetes module ${ }^{25}$ ). 


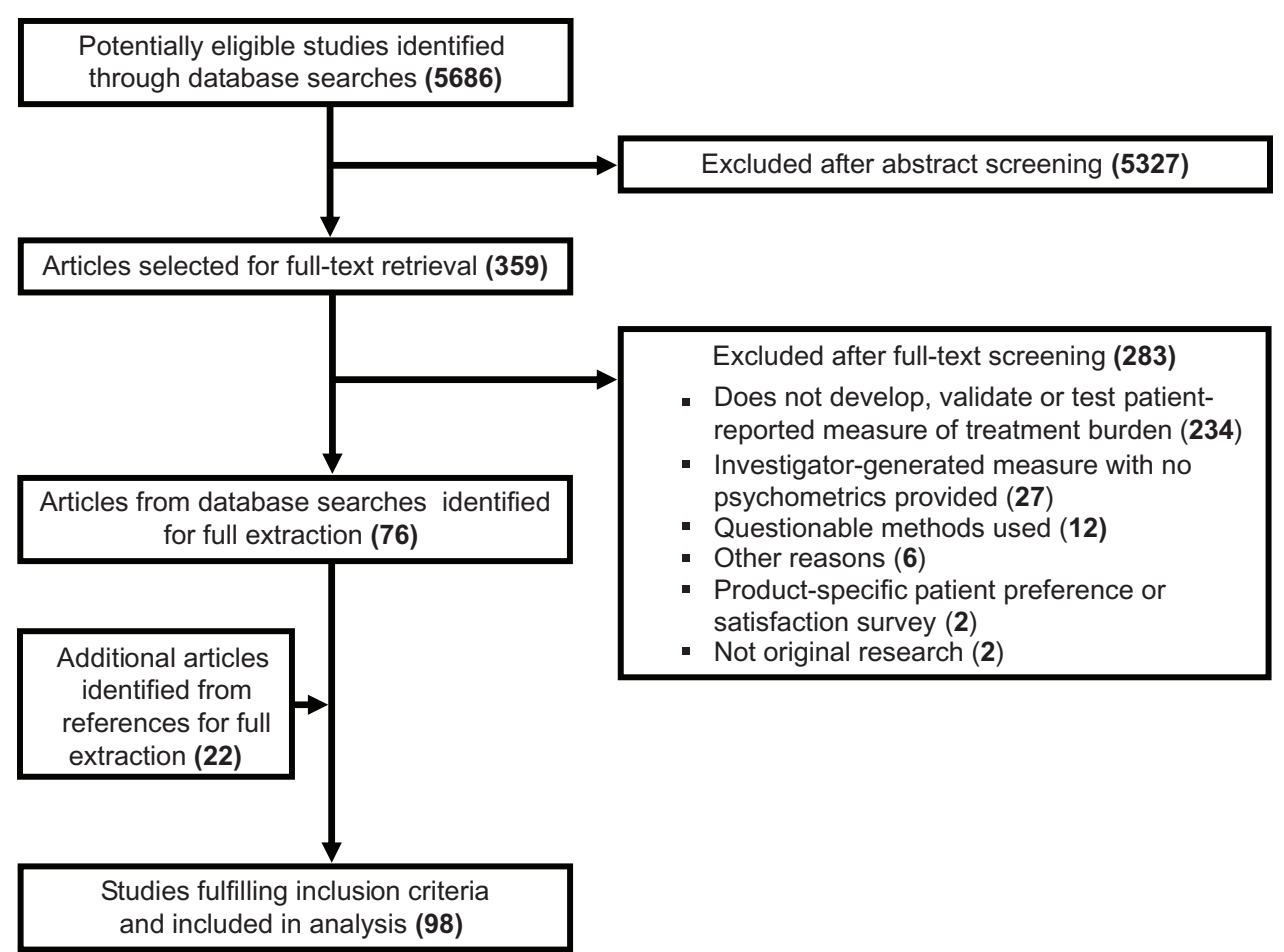

Figure I Flow diagram of study screening and selection.

\section{Common content domains of treatment burden}

Table 2 provides a summary of all measures including a description of the contents of each measure and a summary of key psychometric properties. The instrument name and specific subscales relevant to treatment burden (or scorable components in the case of single items) appear in the first two columns of the table. This information, along with a review of item wording of each relevant measure, provides a general sense of the common content domains reflected in the measures. We identified the following 12 content domains as common to two or more of the identified measures: emotional impact/regimen-related distress, ${ }^{6,23,24,26-38}$ family conflict/ unsupportive behavior from others, ${ }^{39-44}$ convenience of treatment (eg, insulin, oral medications), ${ }^{2,6,19,21,22,24,25,29,38,45-57}$ self-care convenience (eg, exercise, foot care, overall impression of self-care), ${ }^{22,24,25,37,38,48,51,56-60}$ monitoring burden (eg, glucose monitoring), 2,21,22,24,25,38,49,53,56-58,60-63 lifestyle impact (including social restrictions and work interference), ${ }^{2,6,21,24,33,36,37,46,47,50,52,58,62,64,65}$ scheduling flexibility, ${ }^{26,29,46,47}$ medication side effects, ${ }^{29,46,47,55}$ diet/foodrelated problems, ${ }^{2,21,22,25,32,38,48,49,53,55-57,60,66}$ overall treatment burden, ${ }^{18,67}$ device function/bother (eg, insulin delivery device, kidney dialysis), ${ }^{6,34,35,52}$ and economic burden. . $^{20,51,59,68}$ Several measures assess multiple content domains. For example, the DISABKIDS Diabetes module and the Personal
Diabetes Questionnaire each assess five content domains. Eight other measures assess four content domains (Barriers to Adherence Questionnaire, Diabetes Medication Satisfaction Measure, Diabetes Medication Treatment Satisfaction Tool, General Barriers to Diabetes Self-Management, PedsQL 3.0 Diabetes module, Perceived Difficulties in Diabetes SelfCare, Perceptions About Medications for Diabetes, and the Survey of Treatment Burdens in Diabetes).

\section{Psychometric properties of treatment burden measures}

The 98 studies included in this review provided a considerable amount of scale and psychometric data on the identified measures. Detailed tables featuring all extracted data are accessible at http://mayoresearch.mayo.edu/mayo/research/hsr/burdenof-treatment.cfm. Table 2 provides a summary of the extracted data for each measure. Measurement properties featured in the table include patient input, reliability (internal consistency and test-retest), scale analysis (factor analysis, item-total correlation), convergent and discriminant validity, known-groups/concurrent validity, and sensitivity to change. Consistency of each property with a minimum standard of acceptability is indicated in the table.

\section{Patient input}

Directly incorporating patient views during item generation is now considered standard practice when developing a patient-centered, 
Table I Identified patient-reported measures assessing burden of treatment (57)

\section{Diabetes measures (47)}

Treatment/regimen-related impact and burden measures (8)

Diabetic Foot Ulcer Scale

Multidimensional Diabetes Self-Management Checklist

Perceived Burden of Diabetes Treatment (single item)

Perceptions About Medications for Diabetes

Practicality/comfort of treatment (single item)

Survey of Treatment Burdens in Diabetes (individual item scoring)

Treatment-Related Impact Measure - diabetes

Treatment-Related Impact Measure - diabetes device

Barriers to self-care measures (8)

Barriers in Diabetes Questionnaire

Barriers to Adherence Questionnaire

Barriers to Diabetes Adherence ${ }^{\text {child }}$

Diabetes Self-Care Barriers Assessment for Older Adults

Dietary Barriers

General Barriers to Diabetes Self-Management

Perceived Difficulties in Diabetes Self-Care (individual item scoring)

Personal Diabetes Questionnaire

Distress measures (7)

Diabetes Distress Scale (including 2-item, 3-item, and 4-item short versions)

Diabetes Fear of Injecting and Self-testing Questionnaire ${ }^{\text {child }}$

Perceptions of Insulin Shots and Fingersticks (individual item scoring) ${ }^{\text {child }}$

Problem Areas in Diabetes

Insulin treatment measures (6)

Insulin Delivery System Rating Questionnaire

Insulin Pen Questionnaire

Insulin Treatment Appraisal Scale

Insulin Treatment Questionnaire

Insulin Treatment Satisfaction Questionnaire

Patient Satisfaction with Insulin Therapy

Family conflict/strain measures (6)

Diabetes Family Adherence Measure ${ }^{\text {child }}$

Diabetes Family Behavior Checklist ${ }^{\text {child }}$

Diabetes Family Conflict Scale child $^{\text {che }}$

Diabetes Family Support and Conflict Scale

Diabetes Responsibility and Conflict Scale $\mathrm{e}^{\text {child }}$

Multidimensional Diabetes Questionnaire

General diabetes quality-of-life measures (5)

Diabetes-39

Diabetes Health Profile

Diabetes-specific Quality of Life Scale

DISABKIDS Diabetes module child

Pediatric Quality of Life Inventory 3.0 Diabetes module child

Glucose monitoring measures (4)

Blood Glucose Monitoring System Rating Questionnaire

Continuous Glucose Monitoring Satisfaction Scale $e^{\text {child }}$

Glucose Monitoring Surveychild

Measure of Invasiveness as a Reason for Skipping Self-Monitoring of

Glucose

Treatment satisfaction measures (3)

Diabetes Medication Satisfaction Measure

Diabetes Medication Treatment Satisfaction Tool

Treatment Satisfaction Measure for People with Insulin-dependent Diabetes ${ }^{\text {child }}$

(Continued)
Table I (Continued)

Kidney disease measures (6)

Treatment/regimen-related impact and burden measures (2)

Renal Adherence Attitudes Questionnaire

Treatment Effects Questionnaire

Distress measures (2)

Continuous Ambulatory Peritoneal Dialysis Stressor Scale

Hemodialysis Stressor Scale

Barriers to self-care measures (I)

Health Beliefs about Fluid Adherence

Treatment satisfaction measures (I)

Satisfaction with Care Questionnaire

Heart failure measures (4)

Barriers to self-care measures (3)

Beliefs about Dietary Compliance Scale

Beliefs about Medication Compliance Scale

Dietary Sodium Restriction Questionnaire

Treatment/regimen-related impact and burden measures (I)

Perceived difficulty affording health care (single item)

Note: childsuitable for administration to children and adolescents.

self-report measure. ${ }^{11}$ This is typically done using qualitative methods, such as individual interviews or focus groups; however, patient surveys are sometimes used as well. More than half of the measures $(38,67 \%)$ showed evidence of being developed from direct patient input via individual interviews, focus groups, surveys, or combinations of these methods (Table 2).

\section{Reliability}

Internal consistency (Cronbach's alpha) and test-retest (Pearson $\mathrm{r}$ or intraclass correlation) were frequently reported measures of reliability. The standard threshold for acceptable reliability of measures used for group comparison is $0.70 .{ }^{69}$ Most of the measures $(46,81 \%)$ demonstrated acceptable reliability, usually internal consistency (Table 2). Nine measures also demonstrated acceptable test-retest reliability, including the Diabetes Family Adherence Measure, Glucose Monitoring Survey, Insulin Treatment Satisfaction Questionnaire, Perceptions about Medications for Diabetes, Problem Areas in Diabetes, Treatment-Related Impact Measure-Diabetes, Treatment-Related Impact MeasureDiabetes Device, Hemodialysis Stressor Scale, and Renal Adherence Attitudes Questionnaire. Retest magnitudes may have been attenuated in certain measures due to long retest intervals. For example, retest intervals for the Barriers to Adherence and Diabetes Family Behavior Checklist were reported as six months, ${ }^{40,56}$ a span of time in which patient status could have changed. Reliability was unavailable for all measures scoring single items.

\section{Scale analysis}

Content domains apparent in multi-item scales can be verified using factor analysis and item-total scale correlations. 


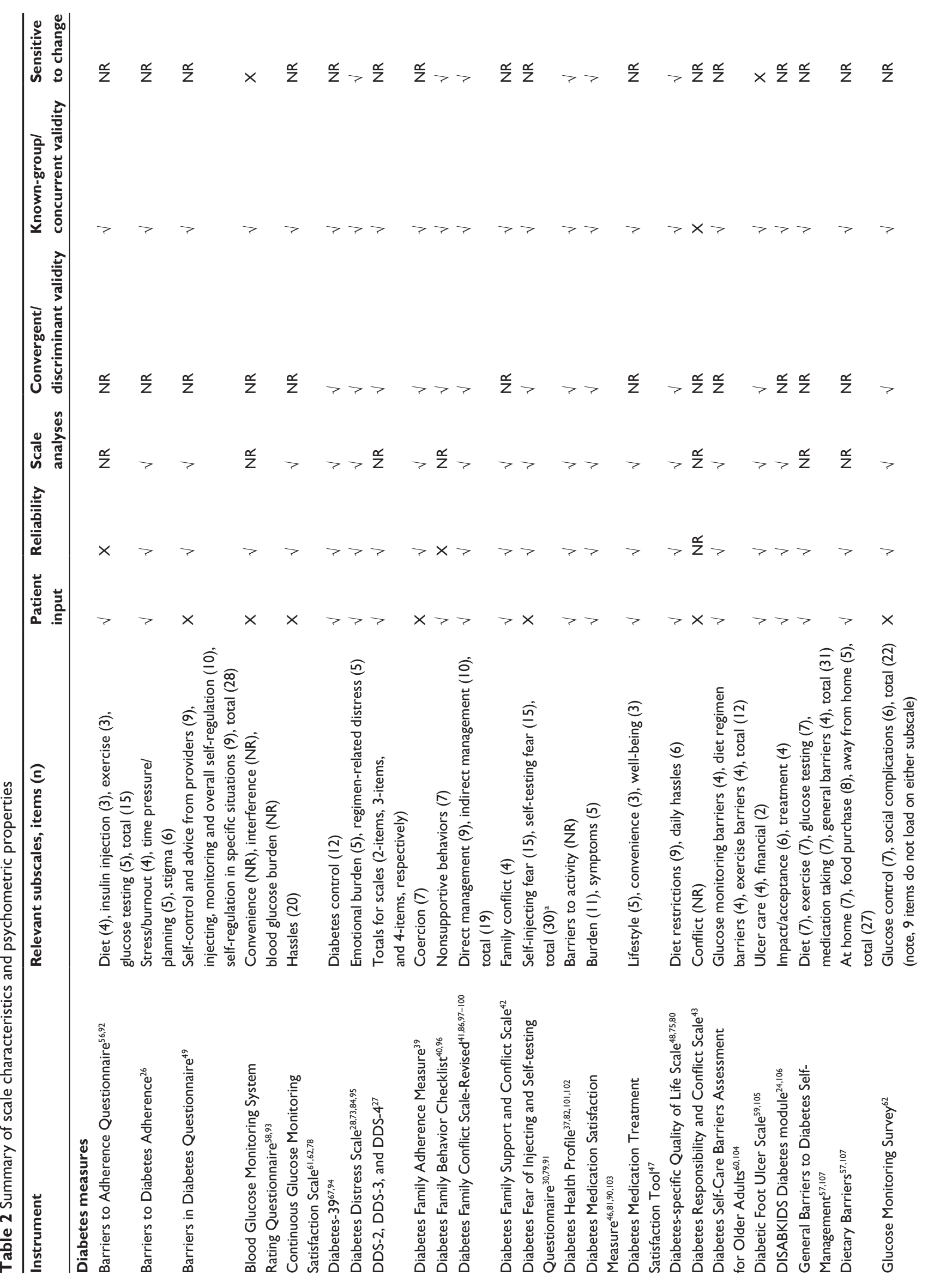




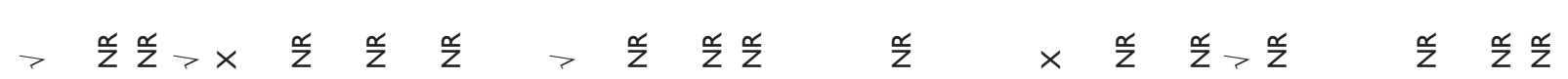

$>>>>>>>$

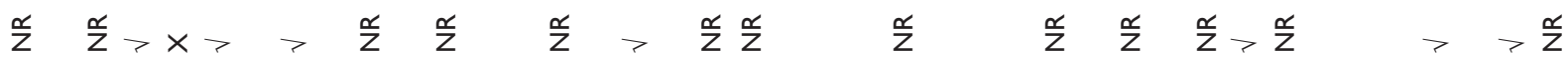

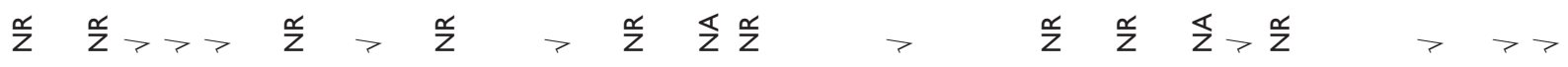

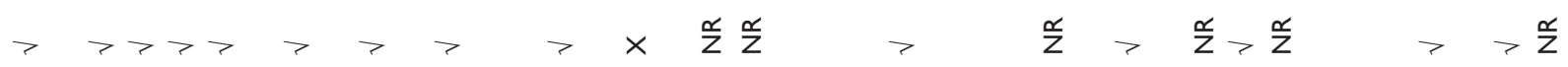

$>>>x>x>x>>x>>>>>>>$

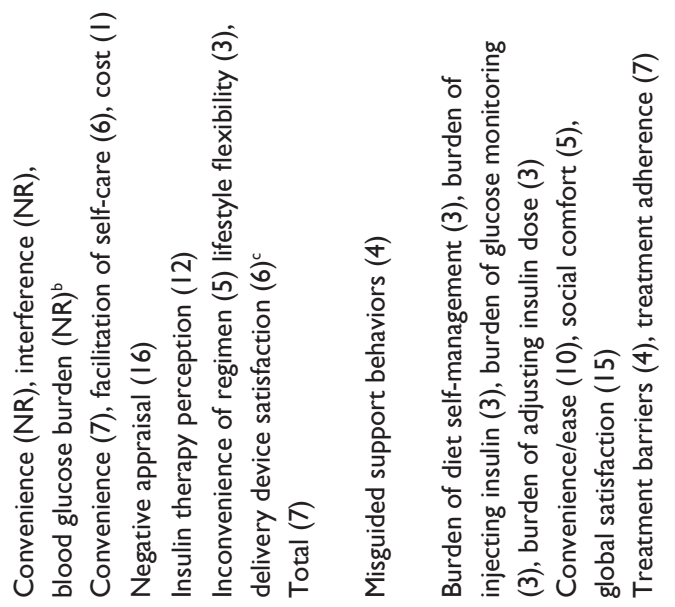

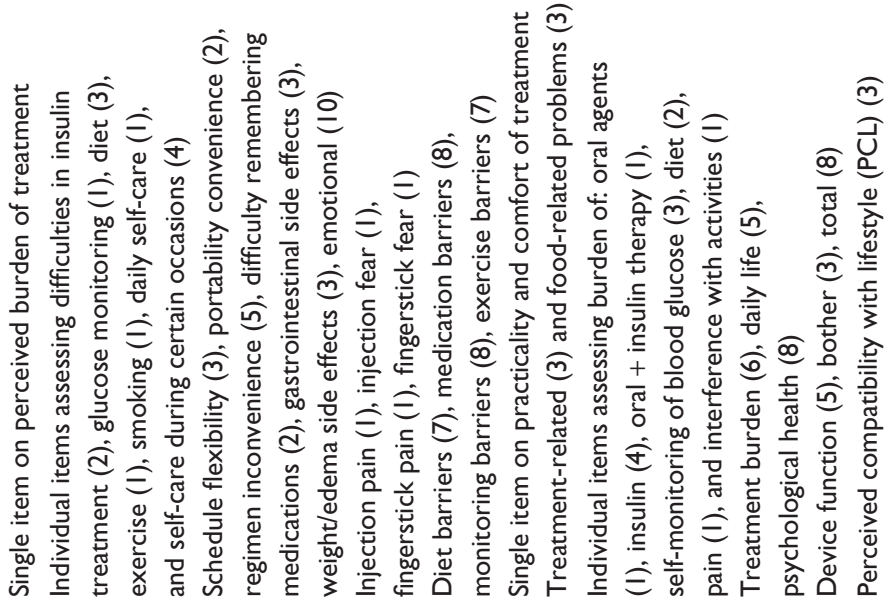
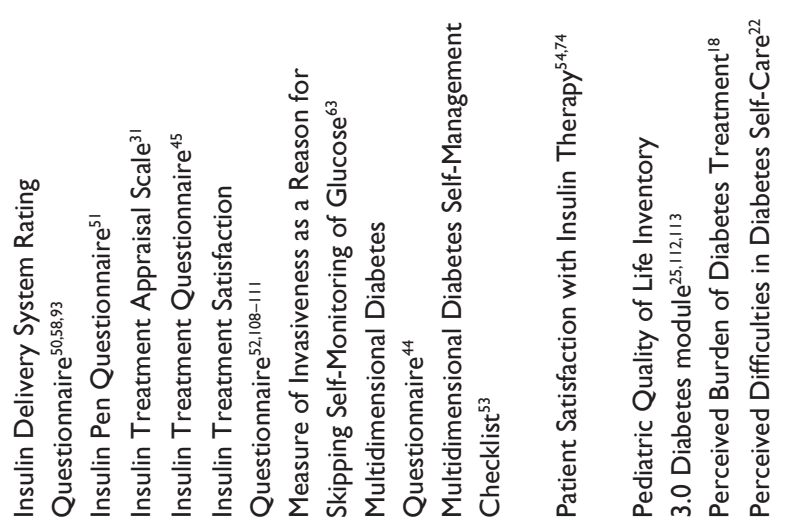

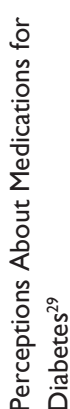
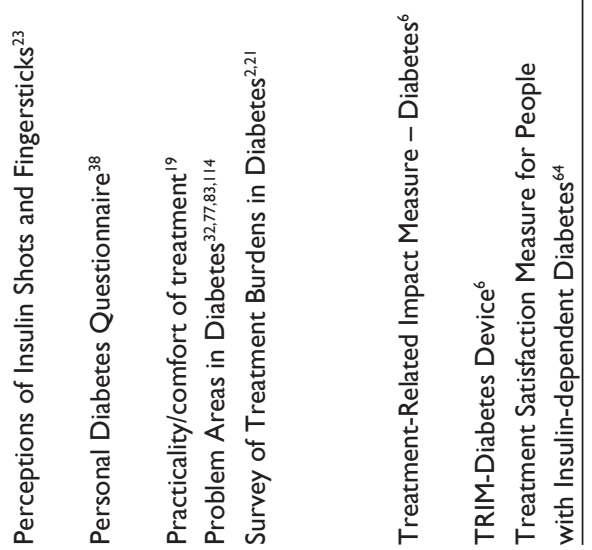


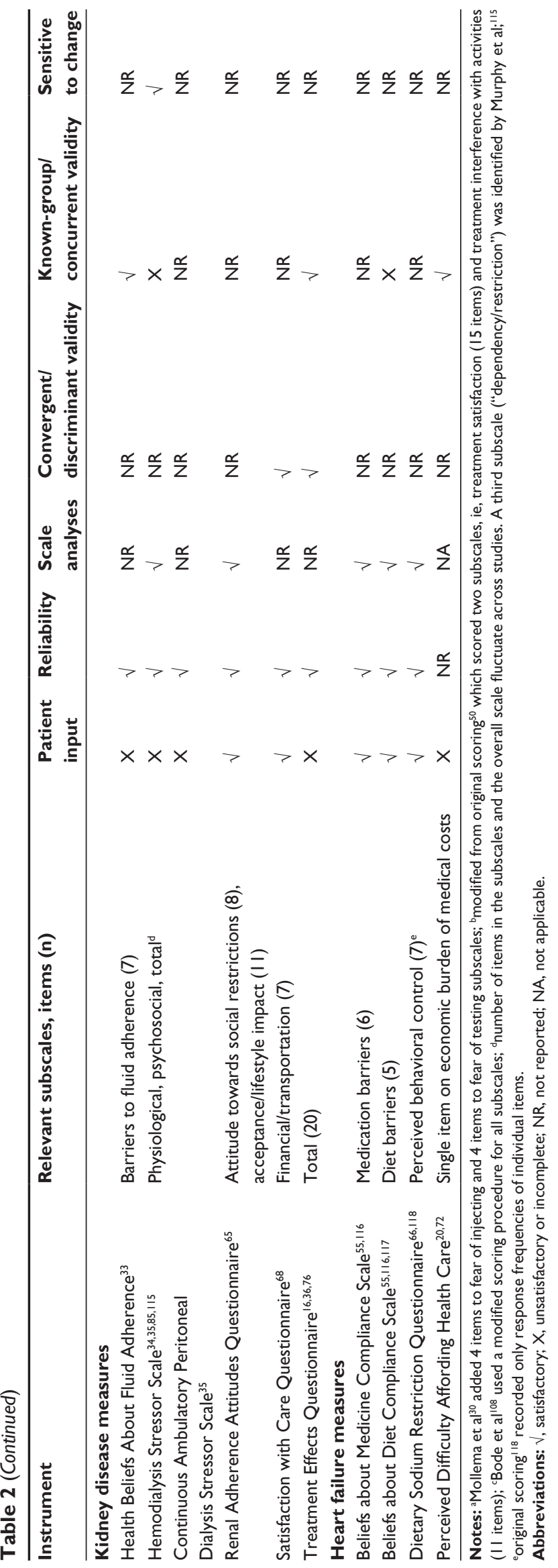

Exploratory factor analytic techniques like principal components analysis and/or confirmatory factor analysis were used in a number of studies, and supported the treatment burden domains identified in most measures (32, 56\%). Exploratory factor analyses typically support content domains through reporting of variance explained; confirmatory factor analysis supports content domains through report of goodness of fit indices. Fifteen of these measures also demonstrated adequate item-total scale correlations (ie, Barriers to Diabetes Adherence, Diabetes-39, Diabetes Family Support and Conflict Scale, Diabetes Fear of Injecting and Self-testing Questionnaire, Diabetes Health Profile, Diabetes-specific Quality of Life Scale, Diabetic Foot Ulcer Scale, Insulin Treatment Appraisal Scale, Insulin Treatment Satisfaction Questionnaire, Patient Satisfaction with Insulin Therapy, Perceptions About Medications for Diabetes, Hemodialysis Stressor Scale, Beliefs about Medicine Compliance Scale, Beliefs about Diet Compliance Scale, and Dietary Sodium Restriction Questionnaire). An adequate item-total scale correlation is $>0.20 .{ }^{14}$

\section{Convergent and discriminant validity}

Convergent validity was determined by the degree of convergence (ie, correlation) of the treatment burden measure with other conceptually similar measures; discriminant validity was determined by the degree of divergence (ie, lack of correlation or low correlation) with other conceptually dissimilar measures. A medium-sized correlation $(r \geq 0.30)^{70}$ may be used to support convergent validity. Discriminant validity is supported by a pattern of low correlations with measures and indicators that are unrelated to the target measure. ${ }^{14}$ As shown in Table 2, less than half of the measures (23, 40\%) demonstrated evidence of convergent or discriminant validity. In most instances, convergent validity alone was supported. For example, in validating the Insulin Treatment Appraisal Scale, Snoek et al found negative insulin appraisal scores were associated with more total diabetes distress on the Problem Areas in Diabetes questionnaire $(\mathrm{r}=0.33) .{ }^{31}$ Among patients with end-stage renal disease, Griva et al found that the total treatment disruptiveness score of the Treatment Effects Questionnaire was strongly associated with the total illness disruptiveness score of the Illness Effects Questionnaire $(r=0.83) .{ }^{36}$ Only four measures showed any evidence of discriminant validity (Diabetes Family Adherence Measure, Insulin Treatment Satisfaction Questionnaire, Problem Areas in Diabetes, and Treatment Effects Questionnaire). ${ }^{32,36,39,52}$ For example, while the coercion scale of the Diabetes Family Adherence Measure has been found to be highly associated 
with the nonsupportive behaviors scale of the Diabetes Family Behavior Checklist $(r=0.65)$, it is much less associated with the warmth/caring $(r=0.22)$ and guidance/control $(r=0.14)$ subscales of the Diabetes Family Behavior Scale. ${ }^{39}$ Evidence of convergent and discriminant validity was absent for measures scoring single items.

\section{Known-groups and concurrent validity}

Clinical utility of the measures was observed in the following ways: by noting differences in scores across meaningful groups of patients (ie, known-groups validity), and by noting correlations of scores with meaningful clinical, health status, or sociodemographic indicators (ie, concurrent validity). Known-groups validity was considered supported if clinically differentiable patient groups differed significantly on the measure in expected ways. ${ }^{71}$ Concurrent validity was evidenced by a statistically significant correlation of at least a moderate magnitude, or in this case $\geq 0.20 .^{70}$ As Table 2 shows, most of the measures $(47,82 \%)$ demonstrated evidence of known-groups and/or concurrent validity. This included five of the six measures scoring single items. . $18,20,22,23,72$ Sample patient groupings on which measure scores significantly differed include continuous glucose monitoring (users versus nonusers), ${ }^{62,73}$ insulin use (yes versus no, type of insulin), ${ }^{31,74,75}$ dialysis type,${ }^{76}$ insurance status, ${ }^{57}$ and mental health status. ${ }^{6,77}$ Clinical indicators such as hemoglobin A1c and adherence with self-care were consistently associated with measure scores across numerous studies, with greater treatment burden associated with higher hemoglobin A1 $\mathrm{c}^{6,25,27,38,39,41,49,54}$ and poorer adherence with selfcare. $2,26,28,40,56,63,64$ Other variables frequently associated with measure scores included age (younger age, more burden) ) $28,78,79^{6}$ and self-reported health (poorer health, more burden). ${ }^{49,67,79}$

\section{Sensitivity to change}

The ability of the treatment burden measure to detect any change in patient status over time (ie, sensitivity to change) $)^{14}$ was noted in a few measures $(11,19 \%$, Table 2$)$. A commonly observed result was a statistically significant decline in treatment burden after a successful medical or psychoeducational intervention..$^{45,58,80-86}$ In only three studies was a standard index of sensitivity also calculated, specifically, Cohen's effect size..$^{45,81,85}$

\section{Patient-centered measures with evidence of reliability and validity}

Of the 57 measures of treatment burden identified in this analysis, 15 (26\%) were developed with direct patient input and had demonstrable evidence of reliability and multiple forms of validity. This included the following measures: Diabetes-39, Diabetes Distress Scale (including the 2-item, 3-item, and 4-item short versions), Diabetes Family Conflict Scale, Diabetes Health Profile, Diabetes Medication Satisfaction Measure, Diabetes-specific Quality of Life Scale, Diabetic Foot Ulcer Scale, Insulin Treatment Appraisal Scale, Insulin Treatment Satisfaction Questionnaire, Problem Areas in Diabetes, Treatment-Related Impact Measure-Diabetes, and Treatment-Related Impact Measure-Diabetes Device. Six of these measures also demonstrated evidence of sensitivity to change (Diabetes Distress Scale, Diabetes Family Conflict Scale, Diabetes Health Profile, Diabetes Medication Satisfaction Measure, Diabetes-specific Quality of Life Scale, and Problem Areas in Diabetes).

\section{Discussion}

To our knowledge, this is the first systematic review of PRMs for burden of treatment. In this review, we identified 57 measures across three chronic conditions, ie, diabetes, kidney disease, and heart failure. There appear to be a number of adequate PRMs tapping various aspects of treatment and self-care burden, mainly in diabetes. Possible explanations for the imbalance in representation favoring diabetes include the self-management complexity of this disease, the fact that diabetes impacts both children and adults, and the speed with which new treatments and management technologies become available for this disease. Indeed, $40 \%$ of the diabetes studies reviewed received funding support from a pharmaceutical or device manufacturer, compared with only $18 \%$ for kidney disease and heart failure studies combined. While our intent in this analysis was not to evaluate the sufficiency of treatment burden measurement in the three targeted conditions, the results appear to support the need for development of more measures in kidney disease and heart failure. No single kidney disease or heart failure measure satisfied all of the psychometric criteria reviewed. Most of the measures reviewed (89\%) are scored as multi-item scales in which multiple items are aggregated to form a score. Measures scoring responses to single items tended to have poorer psychometric properties, with reliability infrequently reported. Also, the availability of measures suitable for administration in children (specifically diabetes) signals the relevance of treatment burden beyond adults.

Several common content domains emerged that cut across the measures and disease types, supporting conceptualization of a general burden of treatment construct. Table 3 shows the 12 content domains that were represented in two or more PRMs. Seven of these domains (emotional impact or regimenrelated distress, treatment convenience, lifestyle impact, 
Table 3 Content domains common across burden of treatment measures

\begin{tabular}{ll}
\hline Emotional impact/regimen-related distress & Scheduling flexibility \\
Family conflict/unsupportive behavior & Medication side effects \\
Treatment convenience & Diet/food-related problems \\
Self-care convenience & Overall treatment burden \\
Monitoring burden & Device function/bother \\
Lifestyle impact (includes social & Economic burden \\
restrictions and work interference) & \\
\hline
\end{tabular}

medication side effects, diet or food-related problems, device function or bother, and economic burden) were represented in PRMs from at least two of the targeted diseases. Economic burden was represented in PRMs of all three diseases. The heterogeneity of the content domains that emerge from these measures lends support to a multidimensional conceptualization of treatment burden, a quality supported by other recent research on the construct, ${ }^{87-89}$ including our own formative qualitative work. ${ }^{1}$

Identifying PRMs of treatment burden required identifying measures of a wide number of related constructs like "barriers to self-care", "distress", "treatment impact", "treatment satisfaction", and "quality of life". Measures of these constructs, many of which are multidimensional, contain elements reflective of treatment burden as well as other concepts. Hence, we needed to examine carefully the components of each measure, including the contents of subscales and even individual items. For example, the Treatment-Related Impact Measure-Diabetes, a measure of treatment impact, contains five subscales, three of which reflect treatment burden (treatment burden, daily life, and psychological health) and two of which do not (management beliefs and compliance). The Diabetes-39, a measure of diabetes-specific quality of life, also consists of five subscales, but only the 12-item control subscale specifically addresses the degree to which treatment and self-care affect quality of life. The other four subscales do not differentiate burden due to the illness from burden due to treatment or self-care. However, there were some instances in which entire measures were judged consistent with the construct of treatment burden (eg, the Diabetes Family Conflict Scale and the Hemodialysis Stressor Scale).

Standard psychometric performance criteria were used to evaluate the quality of each of the identified PRMs. While a review of performance characteristics could help select a measure of treatment burden for use in one of the three diseases targeted, our principal aim was to identify psychometrically sound scales and items that could inform item content for a general non-disease-specific measure. Our review identified 15 measures with acceptable psychometric characteristics in most of the categories extracted including direct patient input, reliability, scaling structure (ie, factor analysis), convergent and/or discriminant validity, and known-groups and concurrent validity. Six of these 15 measures were also sensitive to changes in patient health status over time (the Diabetes Distress Scale, Diabetes Family Conflict Scale, Diabetes Health Profile, Diabetes Medication Satisfaction Measure, Diabetes-specific Quality of Life Scale, and Problem Areas in Diabetes). Authors of a few measures did stipulate clinically meaningful score differences or threshold cut points for serious problems. ${ }^{6,23,90,91}$ There was no evidence of use of more modern psychometric approaches such as item response theory. This is a notable absence given that item response theory-based metrics like item-information and scale-information function and analyses like differential item functioning can provide critical psychometric data that classical test theory methods cannot.

\section{Methodological challenges}

There were several challenges associated with conducting this systematic review. Given that most conceptualizations of treatment burden are of relatively recent origin, developing a literature search strategy that is both sensitive and specific proved difficult. Gallacher et al reported the same challenge in a review of qualitative literature. ${ }^{87}$ Inherent limitations in the way in which articles are currently indexed required that we develop and run a rather broad, highly sensitive but nonspecific, database search strategy. Consequently, our searches identified a large number of articles, most of which failed to meet inclusion criteria for the review. Of the total number of abstracts identified (5686), only 6\% (359) were deemed relevant enough to warrant article retrieval. Of these, only 76 articles (21\%) fulfilled the inclusion criteria and were extracted, or slightly over $1 \%$ of the total number of abstracts identified by the searches. Further, our belief that the burden of treatment is a multidimensional construct also contributed to the expansive nature of the search strategy. Since we expected some variability in the content domains represented in the different measures, the searches consisted of a number of expanded Boolean searches using the "or" connector rather than more limited searches using "and". The nonspecificity of the searches was also compounded by the number of terms synonymous with "patient-reported measure", including "measure", "questionnaire", "instrument", "tool", "scale", and "survey". Finally, during examination of full-text articles, it became apparent that most measures were not designed to assess treatment burden exclusively; hence, it took considerable effort to scrutinize and tease out 
those specific components of each measure that addressed the construct as we defined it.

\section{Limitations}

Our review does have a few limitations. The concept of a general burden of treatment is relatively novel, although we have shown that a number of previously developed PRMs do assess components of it within individual disease contexts. Given that the current state of the science is actively evolving, there is bound to be some disagreement about what does and what does not constitute treatment burden. We attempted to identify domains and PRMs consistent with our own definition of the construct. ${ }^{1}$ It is possible that a different conceptualization could result in identification of a slightly different set of domains and measures. Second, in order to make for a manageable review, we needed to limit the number of chronic conditions. It is possible that a different set of targeted conditions might reveal other content domains not represented in this review. However, we are encouraged by the findings of a recently published concept analysis of the treatment burden literature in six major chronic illnesses that confirms many of the same domains uncovered in our review of measures, including emotional impact, treatment and self-care convenience, lifestyle impact, scheduling flexibility, medication side effects, device function/bother, and economic burden. ${ }^{89}$ Third, study heterogeneity in both methods and the reporting of results precluded use of a more formal quantitative pooling technique such as meta-analysis. Fourth, only English language studies were selected for extraction; hence, we may have missed a few relevant measures unavailable in English. Finally, while all abstracts were reviewed by two people and disagreements were adjudicated by a third reviewer, it is possible that a relevant article was inadvertently excluded by the two abstract reviewers.

\section{Conclusion}

This systematic review of PRMs is a companion piece to our earlier qualitative study that articulated a patient-informed conceptual framework of the burden of treatment. ${ }^{1}$ Most of the content domains identified in this review coincide with themes and subthemes articulated in the framework. Three domains, ie, emotional impact, diet or food-related problems, and device function or bother, are currently not represented in the framework. However, we are continuing to refine this conceptual framework with additional qualitative data from interviews with socioeconomically disadvantaged patients. The ultimate result of all these efforts will be a measurement framework that will provide the foundation on which a patient-centered measure of treatment burden will be built.

\section{Acknowledgments}

This study was funded by Mayo Clinic's Center for Translational Science Activities through grant number UL1 RR024150 from the National Center for Research Resources, a component of the National Institutes of Health. DTE, KJY, and VMM are part of the International Minimally Disruptive Medicine Workgroup. Workgroup members include Victor M Montori, Carl May, Nilay Shah, Frances Mair, Sara Macdonald, Nathan Shippee, Katie Gallacher, David T Eton, Djenane Oliveira, Kathleen J Yost, Robert Stroebel, AnneRose Kaiya, Leona Han, and Amy Bodde. We thank Elie Akl for assistance with an early protocol for the review and Hannah Fields, Krista Bohlen, and Muhammad Mustafa for assistance with abstract screening.

\section{Disclosure}

The authors report no conflicts of interest in this work.

\section{References}

1. Eton DT, Ramalho de Oliveira D, Egginton JS, et al. Building a measurement framework of burden of treatment in complex patients with chronic conditions: a qualitative study. Patient Relat Outcome Meas. 2012;3:39-49. Available from: http://www.ncbi.nlm.nih.gov/pmc/ articles/PMC3506008/. Accessed April 25, 2013.

2. Vijan S, Hayward RA, Ronis DL, Hofer TP. Brief report: the burden of diabetes therapy: implications for the design of effective patient-centered treatment regimens. J Gen Intern Med. 2005;20: 479-482.

3. Haynes RB, McDonald HP, Garg AX. Helping patients follow prescribed treatment: clinical applications. JAMA. 2002;288:2880-2883.

4. Ho PM, Rumsfeld JS, Masoudi FA, et al. Effect of medication nonadherence on hospitalization and mortality among patients with diabetes mellitus. Arch Intern Med. 2006;166:1836-1841.

5. Rasmussen JN, Chong A, Alter DA. Relationship between adherence to evidence-based pharmacotherapy and long-term mortality after acute myocardial infarction. JAMA. 2007;297:177-186.

6. Brod M, Hammer M, Christensen T, Lessard S, Bushnell DM. Understanding and assessing the impact of treatment in diabetes: the Treatment-Related Impact Measures for Diabetes and Devices (TRIMDiabetes and TRIM-Diabetes Device). Health Qual Life Outcomes. 2009;7:83

7. Pifferi M, Bush A, Di Cicco M, et al. Health-related quality of life and unmet needs in patients with primary ciliary dyskinesia. Eur Respir $J$ 2010;35:787-794.

8. May C, Montori VM, Mair FS. We need minimally disruptive medicine BMJ. 2009;339:b2803.

9. Wu S, Green A. Projection of Chronic Illness Prevalence and Cost Inflation. Washington, DC: RAND Health; 2000.

10. Tran VT, Montori VM, Eton DT, Baruch D, Falissard B, Ravaud P. Development and description of measurement properties of an instrument to assess treatment burden among patients with multiple chronic conditions. BMC Med. 2012;10:68.

11. McColl E. Developing questionnaires. In: Fayers P, Hays RD, editors. Assessing Quality of Life in Clinical Trials: Methods and Practice, 2nd ed. New York, NY: Oxford; 2005. 
12. Hays RD, Fayers P. Evaluating multi-item scales. In: Fayers P, Hays RD, editors. Assessing Quality of Life in Clinical Trials: Methods and Practice, 2nd ed. New York, NY: Oxford; 2005.

13. Reeve BB, Fayers P. Applying item response theory modelling for evaluating questionnaire item and scale properties. In: Fayers P, Hays RD, editors. Assessing Quality of Life in Clinical Trials: Methods and Practice, 2nd ed. New York, NY: Oxford; 2005.

14. Streiner DL, Norman GR. Health Measurement Scales: A Practical Guide to Their Development and Use, 4th ed. Oxford, UK: Oxford University Press; 2008.

15. Cowie MR, Zaphiriou A. Management of chronic heart failure. $B M J$. 2002;325:422-425.

16. Jansen DL, Grootendorst DC, Rijken M, et al. Pre-dialysis patients' perceived autonomy, self-esteem and labor participation: associations with illness perceptions and treatment perceptions. A cross-sectional study. BMC Nephrology. 2010;11:35.

17. Nichols GA, Moler EJ. Cardiovascular disease, heart failure, chronic kidney disease and depression independently increase the risk of incident diabetes. Diabetologia. 2011;54:523-526.

18. van der Does FE, de Neeling JN, Snoek FJ, et al. Randomized study of two different target levels of glycemic control within the acceptable range in type 2 diabetes. Effects on well-being at 1 year. Diabetes Care. 1998;21:2085-2093.

19. Lerman I, Diaz JP, Ibarguengoitia ME, et al. Nonadherence to insulin therapy in low-income, type 2 diabetic patients. Endocr Pract. 2009;15: $41-46$.

20. Spertus J, Decker C, Woodman C, et al. Effect of difficulty affording health care on health status after coronary revascularization. Circulation. 2005;111:2572-2578.

21. Vijan S, Stuart NS, Fitzgerald JT, et al. Barriers to following dietary recommendations in type 2 diabetes. Diabet Med. 2005;22:32-38.

22. Toljamo M, Hentinen M. Adherence to self-care and social support. J Clin Nurs. 2001;10:618-627.

23. Howe CJ, Ratcliffe SJ, Tuttle A, Dougherty S, Lipman TH. Needle anxiety in children with type 1 diabetes and their mothers. $M C N, A m$ J Matern Child Nurs. 2011;36:25-31.

24. Baars RM, Atherton CI, Koopman HM, Bullinger M, Power M. The European DISABKIDS project: development of seven conditionspecific modules to measure health related quality of life in children and adolescents. Health Qual Life Outcomes. 2005;3:70.

25. Varni JW, Burwinkle TM, Jacobs JR, Gottschalk M, Kaufman F, Jones KL. The PedsQL in type 1 and type 2 diabetes: reliability and validity of the Pediatric Quality of Life Inventory Generic Core Scales and type 1 Diabetes Module. Diabetes Care. 2003;26:631-637.

26. Mulvaney SA, Hood KK, Schlundt DG, et al. Development and initial validation of the barriers to diabetes adherence measure for adolescents. Diabetes Res Clin Pract. 2011;94:77-83.

27. Fisher L, Glasgow RE, Mullan JT, Skaff MM, Polonsky WH. Development of a brief diabetes distress screening instrument. Ann Fam Med. 2008;6:246-252.

28. Polonsky WH, Fisher L, Earles J, et al. Assessing psychosocial distress in diabetes: development of the diabetes distress scale. Diabetes Care. 2005;28:626-631.

29. Monahan PO, Lane KA, Hayes RP, McHorney CA, Marrero DG. Reliability and validity of an instrument for assessing patients' perceptions about medications for diabetes: the PAM-D. Qual Life Res. 2009;18:941-952.

30. Mollema ED, Snoek FJ, Pouwer F, Heine RJ, van der Ploeg HM. Diabetes Fear of Injecting and Self-Testing Questionnaire: a psychometric evaluation. Diabetes Care. 2000;23:765-769.

31. Snoek FJ, Skovlund SE, Pouwer F. Development and validation of the insulin treatment appraisal scale (ITAS) in patients with type 2 diabetes. Health Qual Life Outcomes. 2007;5:69.

32. Snoek FJ, Pouwer F, Welch GW, Polonsky WH. Diabetes-related emotional distress in Dutch and US diabetic patients: cross-cultural validity of the problem areas in diabetes scale. Diabetes Care. 2000;23: 1305-1309.
33. Welch JL, Perkins SM, Evans JD, Bajpai S. Differences in perceptions by stage of fluid adherence. J Ren Nutr. 2003;13:275-281.

34. Baldree KS, Murphy SP, Powers MJ. Stress identification and coping patterns in patients on hemodialysis. Nurs Res. 1982;31:107-112.

35. Bihl MA, Ferrans CE, Powers MJ. Comparing stressors and quality of life of dialysis patients. ANNA J. 1988;15:27-37.

36. Griva K, Jayasena D, Davenport A, Harrison M, Newman SP. Illness and treatment cognitions and health related quality of life in end stage renal disease. Br J Health Psychol. 2009;14:17-34.

37. Meadows K, Steen N, McColl E, et al. The Diabetes Health Profile (DHP): a new instrument for assessing the psychosocial profile of insulin requiring patients - development and psychometric evaluation. Qual Life Res. 1996;5:242-254.

38. Stetson B, Schlundt D, Rothschild C, Floyd JE, Rogers W, Mokshagundam SP. Development and validation of The Personal Diabetes Questionnaire (PDQ): a measure of diabetes self-care behaviors, perceptions and barriers. Diab Res Clin Pract. 2011;91:321-332.

39. Lewin AB, Geffken GR, Williams LB, Duke DC, Storch EA, Silverstein JH. Development of the Diabetes Family Adherence Measure (D-FAM). Children's Health Care. 2010;39:15-33.

40. Schafer LC, McCaul KD, Glasgow RE. Supportive and nonsupportive family behaviors: relationships to adherence and metabolic control in persons with type I diabetes. Diabetes Care. 1986;9:179-185.

41. Hood KK, Butler DA, Anderson BJ, Laffel LM. Updated and revised Diabetes Family Conflict Scale. Diabetes Care. 2007;30: 1764-1769.

42. Paddison CAM. Family support and conflict among adults with type 2 diabetes: development and testing of a new measure. Eur Diabetes Nursing. 2010;7:29-33.

43. Harris MA, Greco P, Wysocki T, Elder-Danda C, White NH. Adolescents with diabetes from single-parent, blended, and intact families: Health-related and family functioning. Fam Syst and Health. 1999;17:181-196.

44. Talbot F, Nouwen A, Gingras J, Gosselin M, et al. The assessment of diabetes-related cognitive and social factors: The Multidimensional Diabetes Questionnaire. J Behav Med. 1997;20:291-312.

45. Peyrot M, Rubin RR. Effect of technosphere inhaled insulin on quality of life and treatment satisfaction. Diabetes Technol Ther. 2010;12:49-55.

46. Brod M, Skovlund SE, Wittrup-Jensen KU. Measuring the impact of diabetes through patient report of treatment satisfaction, productivity and symptom experience. Qual Life Res. 2006;15:481-491.

47. Anderson RT, Girman CJ, Pawaskar MD, et al. Diabetes medication satisfaction tool. Diabetes Care. 2009;32:51-53.

48. Bott U, Muhlhauser I, Overmann H, Berger M. Validation of a diabetesspecific quality-of-life scale for patients with type 1 diabetes. Diabetes Care. 1998;21:757-769.

49. Mollem ED, Snoek FJ, Heine RJ. Assessment of perceived barriers in self-care of insulin-requiring diabetic patients. Patient Educ Couns. 1996;29:277-281.

50. Peyrot M, Rubin RR. Validity and reliability of an instrument for assessing health-related quality of life and treatment preferences: the insulin delivery system rating questionnaire. Diabetes Care. 2005;28: 53-58.

51. Peyrot M, Rubin RR. Factors associated with persistence and resumption of insulin pen use for patients with type 2 diabetes. Diabetes Technol Ther. 2011;13:43-48.

52. Anderson RT, Skovlund SE, Marrero D, et al. Development and validation of the insulin treatment satisfaction questionnaire. Clin Ther. 2004;26:565-578.

53. Weijman I, Ros WJ, Rutten GE, Schaufeli WB, Schabracq MJ, Winnubst JA. The role of work-related and personal factors in diabetes self-management. Patient Educ Couns. 2005;59:87-96.

54. Cappelleri JC, Gerber RA, Kourides IA, Gelfand RA. Development and factor analysis of a questionnaire to measure patient satisfaction with injected and inhaled insulin for type 1 diabetes. Diabetes Care. 2000;23:1799-1803. 
55. Bennett SJ, Milgrom LB, Champion V, Huster GA. Beliefs about medication and dietary compliance in people with heart failure: An instrument development study. Heart Lung. 1997;26:273-279.

56. Glasgow RE, McCaul KD, Schafer LC. Barriers to regimen adherence among persons with insulin-dependent diabetes. J Behav Med. 1986;9: 65-77.

57. Glasgow RE, Hampson SE, Strycker LA, Ruggiero L. Personal-model beliefs and social-environmental barriers related to diabetes selfmanagement. Diabetes Care. 1997;20:556-561.

58. Rubin RR, Peyrot M. Treatment satisfaction and quality of life for an integrated continuous glucose monitoring/insulin pump system compared to self-monitoring plus an insulin pump. J Diabetes Sci Technol. 2009;3:1402-1410.

59. Abetz L, Sutton M, Brady L, McNulty P, Gagnon DD. The Diabetic Foot Ulcer Scale (DFS): a quality of life instrument for use in clinical trials. Practical Diabetes Int. 2002;19:167-175.

60. Tu KS, Barchard K. An assessment of diabetes self-care barriers in older adults. J Community Health Nurs. 1993;10:113-118.

61. Diabetes Research in Children Network Study Group. Youth and parent satisfaction with clinical use of the GlucoWatch G2 Biographer in the management of pediatric type 1 diabetes. Diabetes Care. 2005;28: 1929-1935.

62. Juvenile Diabetes Research Foundation Continuous Glucose Monitoring Study Group. Validation of measures of satisfaction with and impact of continuous and conventional glucose monitoring. Diabetes Technol Ther. 2010;12:679-684.

63. Wagner J, Malchoff C, Abbott G. Invasiveness as a barrier to selfmonitoring of blood glucose in diabetes. Diabetes Technol Ther. 2005; 7 : 612-619.

64. Lewis KS, Bradley C, Knight G, Boulton AJ, Ward JD. A measure of treatment satisfaction designed specifically for people with insulindependent diabetes. Diabet Med. 1988;5:235-242.

65. Rushe H, McGee HM. Assessing adherence to dietary recommendations for hemodialysis patients: the Renal Adherence Attitudes Questionnaire (RAAQ) and the Renal Adherence Behaviour Questionnaire (RABQ). J Psychosom Res. 1998;45:149-157.

66. Bentley B, Lennie TA, Biddle M, Chung ML, Moser DK. Demonstration of psychometric soundness of the Dietary Sodium Restriction Questionnaire in patients with heart failure. Heart Lung 2009;38:121-128.

67. Boyer JG, Earp JA. The development of an instrument for assessing the quality of life of people with diabetes. Diabetes-39. Med Care. 1997;35:440-453.

68. Ferrans CE, Powers MJ, Kasch CR. Satisfaction with health care of hemodialysis patients. Res Nurs Health. 1987;10:367-374.

69. Frost MH, Reeve BB, Liepa AM, Stauffer JW, Hays RD. What is sufficient evidence for the reliability and validity of patient-reported outcome measures? Value Health. 2007;10 Suppl 2:S94-S105.

70. Cohen J. Statistical Power Analysis for the Behavioral Sciences, 2nd ed. Hillsdale, NJ: Lawrence Erlbaum Associates; 1988.

71. Osoba D, King M. Meaningful differences. In: Fayers P, Hays RD, editors. Assessing Quality of Life in Clinical Trials: Methods and Practice, 2nd ed. New York, NY: Oxford; 2005.

72. Conard MW, Heidenreich P, Rumsfeld JS, Weintraub WS, Spertus J. Patient-reported economic burden and the health status of heart failure patients. J Card Fail. 2006;12:369-374.

73. Halford J, Harris C. Determining clinical and psychological benefits and barriers with continuous glucose monitoring therapy. Diabetes Technol Ther. 2010;12:201-205.

74. Cappelleri JC, Cefalu WT, Rosenstock J, Kourides IA, Gerber RA. Treatment satisfaction in type 2 diabetes: a comparison between an inhaled insulin regimen and a subcutaneous insulin regimen. Clin Ther. 2002;24:552-564.

75. Nicolucci A, Maione A, Franciosi M, et al. Quality of life and treatment satisfaction in adults with type 1 diabetes: a comparison between continuous subcutaneous insulin infusion and multiple daily injections. Diabet Med. 2008;25:213-220.
76. Griva K, Davenport A, Harrison M, Newman S. An evaluation of illness, treatment perceptions, and depression in hospital- vs home-based dialysis modalities. J Psychosom Res. 2010;69:363-370.

77. Kokoszka A, Pouwer F, Jodko A, et al. Serious diabetes-specific emotional problems in patients with type 2 diabetes who have different levels of comorbid depression: a Polish study from the European Depression in Diabetes (EDID) Research Consortium. Eur Psychiatry. 2009;24: 425-430.

78. Tansey M, Laffel L, Cheng J, et al. Satisfaction with continuous glucose monitoring in adults and youths with type 1 diabetes. Diabet Med. 2011;28:1118-1122.

79. Snoek FJ, Mollema ED, Heine RJ, Bouter LM, van der Ploeg HM. Development and validation of the diabetes fear of injecting and self-testing questionnaire (D-FISQ): first findings. Diabet Med. 1997; 14:871-876.

80. Bott U, Ebrahim S, Hirschberger S, Skovlund SE. Effect of the rapid-acting insulin analogue insulin aspart on quality of life and treatment satisfaction in patients with type 1 diabetes. Diabet Med. 2003;20:626-634.

81. Brod M, Valensi P, Shaban JA, Bushnell DM, Christensen TL. Patient treatment satisfaction after switching to NovoMix 30 (BIAsp 30) in the IMPROVE study: an analysis of the influence of prior and current treatment factors. Qual Life Res. 2010;19:1285-1293.

82. George JT, Valdovinos AP, Russell I, et al. Clinical effectiveness of a brief educational intervention in type 1 diabetes: results from the BITES (Brief Intervention in Type 1 diabetes, Education for Self-efficacy) trial. Diabet Med. 2008;25:1447-1453.

83. Keers JC, Groen H, Sluiter WJ, Bouma J, Links TP. Cost and benefits of a multidisciplinary intensive diabetes education programme. $J$ Eval Clin Pract. 2005;11:293-303.

84. Peyrot M, Rubin RR, Polonsky WH, Best JH. Patient reported outcomes in adults with type 2 diabetes on basal insulin randomized to addition of mealtime pramlintide or rapid-acting insulin analogs. Curr Med Res Opin. 2010;26:1047-1054.

85. Tsay SL, Lee YC, Lee YC. Effects of an adaptation training programme for patients with end-stage renal disease. JAdv Nurs. 2005;50:39-46.

86. de Wit M, Delmarre-van de Waal HA, Bokma JA, et al. Follow-up results on monitoring and discussing health-related quality of life in adolescent diabetes care: benefits do not sustain in routine practice. Pediatr Diabetes. 2010;11:175-181.

87. Gallacher K, Jani B, Morrison D, et al. Qualitative systematic reviews of treatment burden in stroke, heart failure and diabetes - methodological challenges and solutions. BMC Med Res Methodol. 2013;13:10.

88. Gallacher K, May CR, Montori VM, Mair FS. Understanding patients' experiences of treatment burden in chronic heart failure using normalization process theory. Ann Fam Med. 2011;9:235-243.

89. Sav A, King MA, Whitty JA, et al. Burden of treatment for chronic illness: a concept analysis and review of the literature. Health Expect. January 31, 2013. [Epub ahead of print.]

90. Brod M, Christensen T, Kongso JH, Bushnell DM. Examining and interpreting responsiveness of the Diabetes Medication Satisfaction measure. J Med Econ. 2009;12:309-316.

91. Simmons JH, McFann KK, Brown AC, et al. Reliability of the Diabetes Fear of Injecting and Self-Testing Questionnaire in pediatric patients with type 1 diabetes. Diabetes Care. 2007;30:987-988.

92. Khattab M, Khader YS, Al-Khawaldeh A, Ajlouni K. Factors associated with poor glycemic control among patients with type 2 diabetes. J Diabetes Complications. 2010;24:84-89.

93. Peyrot M, Rubin RR. Patient-reported outcomes for an integrated realtime continuous glucose monitoring/insulin pump system. Diabetes Technol Ther. 2009;11:57-62.

94. Khader YS, Bataineh S, Batayha W. The Arabic version of Diabetes-39: psychometric properties and validation. Chronic Illn. 2008;4: 257-263.

95. Trief PM, Teresi JA, Izquierdo R, et al. Psychosocial outcomes of telemedicine case management for elderly patients with diabetes: the randomized IDEATel trial. Diabetes Care. 2007;30:1266-1268. 
96. Ott J, Greening L, Palardy N, Holderby A, DeBell WK. Self-efficacy as a mediator variable for adolescents' adherence to treatment for insulin-dependent diabetes mellitus. Children's Health Care. 2000;29:47-63.

97. Anderson BJ, Holmbeck G, Iannotti RJ, et al. Dyadic measures of the parent-child relationship during the transition to adolescence and glycemic control in children with type 1 diabetes. Fam Syst Health. 2009;27:141-152.

98. Muller-Godeffroy E, Treichel S, Wagner VM. Investigation of quality of life and family burden issues during insulin pump therapy in children with type 1 diabetes mellitus - a large-scale multicentre pilot study. Diabet Med. 2009;26:493-501.

99. Sander EP, Odell S, Hood KK. Diabetes-specific family conflict and blood glucose monitoring in adolescents with type 1 diabetes: mediational role of diabetes self-efficacy. Diabetes Spectr. 2010;23: 89-94.

100. de Wit M, Delemarre-van de Waal HA, Bokma JA, et al. Monitoring and discussing health-related quality of life in adolescents with type 1 diabetes improve psychosocial well-being: a randomized controlled trial. Diabetes Care. 2008;31:1521-1526.

101. Cleveringa FG, Minkman MH, Gorter KJ, van den Donk M, Rutten GE. Diabetes Care Protocol: effects on patient-important outcomes. A cluster randomized, non-inferiority trial in primary care. Diabet Med. 2010;27:442-450.

102. Gorter KJ, Tuytel GJ, de Leeuw RR, Bensing JM, Rutten GE. Opinions of patients with type 2 diabetes about responsibility, setting targets and willingness to take medication. A cross-sectional survey. Patient Educ Couns. 2011;84:56-61.

103. Williams SA, Pollack MF, DiBonaventura M. Effects of hypoglycemia on health-related quality of life, treatment satisfaction and healthcare resource utilization in patients with type 2 diabetes mellitus. Diabetes Res Clin Pract. 2011;91:363-370.

104. Schoenberg NE, Drungle SC. Barriers to non-insulin dependent diabetes mellitus (NIDDM) self-care practices among older women. J Aging Health. 2001;13:443-466.

105. Bann CM, Fehnel SE, Gagnon DD. Development and validation of the Diabetic Foot Ulcer Scale-short form (DFS-SF). Pharmacoeconomics. 2003;21:1277-1290.

106. Chaplin JE, Hanas R, Lind A, Tollig H, Wramner N, Lindblad B. Assessment of childhood diabetes-related quality-of-life in West Sweden. Acta Paediatr. 2009;98:361-366.
107. Wen LK, Parchman ML, Shepherd MD. Family support and diet barriers among older Hispanic adults with type 2 diabetes. Fam Med. 2004;36:423-430.

108. Bode B, Shelmet J, Gooch B, et al. Patient perception and use of an insulin injector/glucose monitor combined device. Diabetes Educ. 2004;30:301-309.

109. Brod M, Christensen T, Bushnell D. Maximizing the value of validation findings to better understand treatment satisfaction issues for diabetes. Qual Life Res. 2007;16:1053-1063.

110. Brod M, Cobden D, Lammert M, Bushnell D, Raskin P. Examining correlates of treatment satisfaction for injectable insulin in type 2 diabetes: lessons learned from a clinical trial comparing biphasic and basal analogues. Health Qual Life Outcomes. 2007;5:8.

111. Farmer AJ, Oke J, Stevens R, Holman RR. Differences in insulin treatment satisfaction following randomized addition of biphasic, prandial or basal insulin to oral therapy in type 2 diabetes. Diabetes Obes Metab. 2011;13:1136-1141.

112. Allan CL, Flett B, Dean HJ. Quality of life in First Nation youth with type 2 diabetes. Matern Child Health J. 2008;12:S103-S109.

113. McCarty RL, Weber WJ, Loots B, et al. Complementary and alternative medicine use and quality of life in pediatric diabetes. J Altern Complement Med. 2010;16:165-173.

114. McGuire BE, Morrison TG, Hermanns N, et al. Short-form measures of diabetes-related emotional distress: the Problem Areas in Diabetes Scale (PAID)-5 and PAID-1. Diabetologia. 2010;53:66-69.

115. Murphy SP, Powers MJ, Jalowiec A. Psychometric evaluation of the Hemodialysis Stressor Scale. Nurs Res. 1985;34:368-371.

116. Bennett SJ, Perkins SM, Lane KA, Forthofer MA, Brater DC, Murray MD. Reliability and validity of the compliance belief scales among patients with heart failure. Heart Lung. 2001;30:177-185.

117. Nieuwenhuis MMW, van der Wal MHL, Jaarsma T. The body of knowledge on compliance in heart failure patients: we are not there yet. J Cardiovasc Nurs. 2011;26:21-28.

118. Lennie TA, Worrall-Carter L, Hammash M, et al. Relationship of heart failure patients' knowledge, perceived barriers, and attitudes regarding low-sodium diet recommendations to adherence. Prog Cardiovasc Nurs. 2008;23:6-11.
Patient Related Outcome Measures

\section{Publish your work in this journal}

Patient Related Outcome Measures is an international, peer-reviewed, open access journal focusing on treatment outcomes specifically relevant to patients. All aspects of patient care are addressed within the journal and practitioners from all disciplines are invited to submit their work as well as healthcare researchers and patient support groups.

\section{Dovepress}

The manuscript management system is completely online and includes a very quick and fair peer-review system. Visit http://www.dovepress. com/testimonials.php to read real quotes from published authors. 